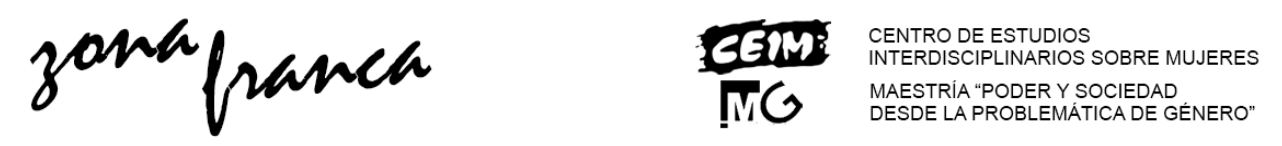

\title{
Escritoras, entre el canon y el cupo: un breve recorrido por las historias de la literatura argentina
}

\author{
Clara Charrúa* \\ "Que se vuelva a narrar la historia para comprender las razones" \\ María Pía López, 2019
}

\section{Resumen}

En este trabajo me propongo analizar la diferencia sexual en las historias de la literatura argentina, atendiendo a las formas de exclusión y a las condiciones de inclusión de la literatura de escritoras pertenecientes a las primeras décadas del siglo XX. La tradición crítica de historiografía literaria e intervenciones sobre el canon literario fue articulada en los trabajos de Pollock (2019) y Maradei (2012). Si bien esta producción fue estudiada por la crítica literaria feminista, la categoría "mujer" seguirá siendo tanto clave de lectura como condición de exclusión en los relatos de máxima autoridad del canon literario. A pesar de eso la literatura producida por mujeres no deja de aparecer como carta de intención y asunto pendiente de la crítica literaria, historia tras historia de la literatura.

Palabras clave: Canon literario - Historias de la literatura argentina - Escritoras - Intervención

\section{Female writers, between the canon and the quota: a short journey through Argentine literature histories}

\section{Abstract}

In this work I propose to analyze the sexual difference in the Argentine literature histories, paying attention to the forms of exclusion and the conditions of inclusion of the literature of female writers from the first decades of the 20th century. The

*Universidad de Buenos Aires. Contacto: charruaclara@gmail.com

Charrúa, Clara. "Escritoras, entre el canon y el cupo: un breve recorrido por las historias de la literatura argentina" en Zona Franca. Revista del Centro de estudios Interdisciplinario sobre las Mujeres, y de la Maestría poder y sociedad desde la problemática de Género, №28, 2020 pp. 456482. ISSN, 2545-6504 Recibido: 28 de julio 2020; Aceptado: 11 de octubre 2020

Revista Zona Franca- Centro de estudios interdisciplinario sobre las mujeres (CEIM)- Maestría poder y sociedad desde la problemática de género (MG), Rosario, Argentina. ISSN, 2545-6504 http://zonafranca.unr.edu.ar/index.php/ZonaFranca| Número 28 (2020). 
critical tradition of literary historiography and interventions on the literary canon was articulated in the works of Pollock (2019) and Maradei (2012). Although this production was studied by feminist literary criticism, the category "woman" will continue to be both a key to reading and a condition of exclusion in the most authoritative narration of the literary canon. Nevertheless, the literature produced by women does not cease to appear as a letter of intent and pending issue for literary criticism, history after history of literature.

Key words: Literary canon - Argentine literature histories - female writers - Intervention

\section{Introducción}

Los procesos de canonización acompañan procesos políticos, sociales y culturales mediante los cuales un texto o expresión literaria puede entenderse como la manifestación de particularidades de un momento histórico concreto, en un espacio concreto así como soportes de efectos culturales (Prieto, 2006). Las historias de la literatura permiten no solo comprender las "historizaciones de las prácticas literarias", sino también "su recepción crítica" (Maradei, 2012: 158). En el caso de la Argentina, cada historia es un programa de análisis crítico y político que teje aparatos de lectura particulares en relación con los paradigmas contextuales, y también en diálogo con las historias de la literatura argentinas anteriores. A la vez, como destaca Jorge Panesi "escribir una historia literaria es un momento de recapitulación y de prueba a que la propia crítica se somete" (2019: 383). De este modo, las distintas historias de la literatura se han constituido a través del tiempo como máxima autoridad a la hora de definir y delimitar un canon literario como panteón de textos dignos de ser estudiados, leídos, enseñados. En aquellas interacciones entre el canon y el corpus (Mignolo, 1995), existen expresiones literarias oscurecidas por cierta noción de literatura que identifica y homologa unilateralmente al canon con todo el campo de los estudios literarios. Ejemplos de estas expresiones oscurecidas son las producciones de las escritoras mujeres. A primera vista, hablar de "escritoras mujeres" parece ser redundante ya que si

Revista Zona Franca- Centro de estudios interdisciplinario sobre las mujeres (CEIM)- Maestría poder y sociedad desde la problemática de género (MG), Rosario, Argentina. ISSN, 2545-6504 http://zonafranca.unr.edu.ar/index.php/ZonaFrancal Número 28 (2020). 
alguien dice "escritoras", por cómo funciona nuestro sistema nominal, se desprende que son mujeres $\mathrm{o}$, mejor dicho, identidades entendidas y asociadas socialmente como pertenecientes al género femenino.' Sin embargo, la redundancia resulta productiva para pensar la inclusión o la exclusión de estas escritoras en las historias de la literatura y ciertos modos de la crítica literaria que reproducen la diferencia sexual (Pollock, 2019)." ¿Acaso la condición de "mujer" prevalece, a la hora de estudiar su producción, por sobre la de "escritora", incluso por sobre la de "obra"? ¿es posible que la categoría "mujer" funcione como clave de lectura a la hora de insertar escritoras en el relato de la historia literaria, con intención de cumplir cierto imperativo de "cupo", o como condición de exclusión?

Con la lupa teñida por estas interrogaciones analizaré ciertas figuraciones de escritoras cuyas producciones abarcaron las primeras décadas del siglo XX en las historias de la literatura argentina." El recorte histórico fue trazado atendiendo a la importancia que tuvo este período en la forja de la literatura como oficio, profesión

' En este punto es preciso retomar a Nelly Richard (2008). Cuando se dice "mujeres", se da cuenta de la identidad como "producto de las complejas tramas de representaciones y poder que se imprimen en los cuerpos sexuados atravesando los discursos simbólicos de la cultura" (157). Estas definiciones, al igual que la de diferencia sexual para los feminismos latinoamericanos, se desarrollan en el trabajo de esta autora Feminismo, género y diferencia(s).

"La definición de este concepto fundamental es la elaborada por Pollock en sus relecturas de Braidotti (2004) e Irigaray (2004), que considera a la diferencia sexual aquel estereotipo que opera como criterio analítico. Es decir que las mujeres han sido efectivamente parte de la historia del arte pero en la recepción y en la historiografía sus obras se amalgaman con una presunta "femenidad" construida como cualidad (causa y consecuencia) inherente a las mismas, y a la vez con un "mal arte" (Pollock, 2019: 62). Esto trae como efecto el descarte y mantenimiento del privilegio masculino en las distintas disciplinas artísticas y en los estratos de estudios, circulaciones y críticas de las mismas.

III Me refiero al Tomo IV de la Historia de la literatura argentina de Rafael Arrieta (1959); la Historia del Centro Editor de América Latina (ediciones de 1968 y 1981, esta última compilada y publicada por Susana Zanetti en 6 tomos, del cual tomaré el número III y el IV); la Literatura argentina y realidad política de David Viñas (realizando el cotejo entre las ediciones de 1964, 1971, 1995 y 2005); los tomos II (2006) y III (2007) de Literatura argentina siglo XX a cargo de Graciela Montaldo y María Pía López respectivamente; la Breve historia de la literatura argentina de Martín Prieto (2006); los tomos VI (2002) y VII (2009) y de la Historia crítica de la literatura argentina, a cargo de María Teresa Gramuglio y Celina Manzoni respectivamente. La Historia de la literatura argentina. Ensayo filosófico sobre la evolución de la cultura en el Plata, de Ricardo Rojas (1917), por tratarse de un texto contemporáneo al período analizado, fue excluido. Sin embargo al ser la primera de todas las historias de la literatura, diversos elementos allí diagramados están presentes en las historias que le siguen ya que todas lo retoman, como punto de partida o para leer a contrapelo ciertos paradigmas allí estructurados.

Revista Zona Franca- Centro de estudios interdisciplinario sobre las mujeres (CEIM)- Maestría poder y sociedad desde la problemática de género (MG), Rosario, Argentina. ISSN, 2545-6504 http://zonafranca.unr.edu.ar/index.php/ZonaFrancal Número 28 (2020).

Página 458 
y arte autónomo, independiente de las esferas estatales y de la élite política. Forja que no hubiera sido posible sin la existencia de un público masivo alfabetizado que comenzaba a constituir una de las grandes columnas vertebrales de la industria cultural argentina (Sarlo, 1988). Otra de estas columnas fue la cantidad y diversidad de canales de difusión y circulación de la producción literaria como la prensa escrita, las revistas, y todo el espectro de actividades referidas a la consagración de la esfera intelectual (cafés, tertulias, debates, entre otros ámbitos). En este sentido, los debates y contiendas en relación a diversos aspectos de la lengua y la literatura como la tradición, el idioma y la historia literaria fueron característicos del período. $\mathrm{Si}$ el desierto que era el territorio precisaba de su Nación Argentina, esta como comunidad imaginada merecía también su literatura nacional. Las relaciones presentes y los efectos de la experiencia moderna en los sujetos, señala Sarlo, se reordenan simbólicamente en las manifestaciones y constituciones del campo intelectual. Las producciones de este período hacen eco de este ordenamiento y sientan posiciones estéticas y políticas. En el plano de las instituciones, se fundan una serie de espacios ligados a esta consolidación, como la cátedra de Literatura Argentina en 1913, el Instituto de Filología en 1922 y la Academia Argentina de Letras en 1931. Esto convierte a estas décadas en un período decisivo para la edificación de un imaginario literario en torno a lo nacional que debía presentarse a sí mismo como lo más uniforme posible. En aquella homogeneización, como señalan Alicia Salomone (2006) y Francine Masiello (1998), desde las instituciones se perfila también un modelo de mujer profesional cuya intención era paliar la desestabilización de lo esperado y lo establecido en el período anterior como único destino posible para las identidades femeninas. Con el ingreso de las mujeres al mercado (Queirolo, 2004), una serie de reglamentaciones y producciones en torno a este sujeto político se empiezan a diagramar en la esfera literaria y en el campo intelectual en general. Un efecto de esto fue la resistencia de las escritoras desde su literatura, militancia y activismo político a este modelo institucional coercitivo, que reproducía cierta de imagen de mujer y una moral disciplinadora en relación a la sexualidad, la sentimentalidad y la socialización. Entre las redacciones de revistas

Revista Zona Franca- Centro de estudios interdisciplinario sobre las mujeres (CEIM)- Maestría poder y sociedad desde la problemática de género (MG), Rosario, Argentina. ISSN, 2545-6504 http://zonafranca.unr.edu.ar/index.php/ZonaFranca| Número 28 (2020). Página 459 
ubicadas en calles del Norte y del Sur de la ciudad, entre las orillas, los compadritos y las resignificaciones vanguardistas de la progenie europea, la modernidad porteña acogía como sujetas políticas a las escritoras que, si no participaban de los debates más populares y conocidos del momento sobre la literatura, escribían en diversos medios de comunicación. Como señala Tania Diz, en el imaginario de estas décadas y ante la afluencia de mujeres productoras (de trabajo, de literatura) "la reacción de los sectores dominantes consistió fundamentalmente en la afirmación de las diferencias sexuales, con el objetivo de controlar a las mujeres y sujetarlas al reglamento de género" (2012: 3). IV Si todas las historias de la literatura se entretejen en diálogo con esta primera elaborada por Ricardo Rojas en 1917, representante de los intereses de estos sectores dominantes que menciona la autora, era de esperarse que en esos modos canónicos de hacer y de perfilar la crítica literaria las diferencias sexuales también se reprodujeran. Es decir que no solamente había una intención activa de consolidar una imagen de literatura homogénea, sino de que esta imagen fuese funcional a los estereotipos de género que la sociedad argentina de principios de siglo XX necesitaba. Sin embargo, ¿qué pasó después de más de un siglo de historia y crítica literaria? ¿es posible desmontar, aún en el relato canónico de la historia literaria, los procedimientos críticos que reproducen en su entramado las diferencias sexuales? Como primer paso analizaré los modos de estudio e incorporación a las distintas historias de la literatura de estas mujeres y sus escritos, qué se dice de las mujeres que figuran. Y los mecanismos de exclusión. Atenderé no solamente el número de escritoras que hay en relación con la cantidad de escritores, sino también a la información que se jerarquiza en estas menciones, a la metodología crítica y a las claves de lectura que se ofrecen, si es que se ofrecen.

\footnotetext{
IV Para profundizar sobre estas cuestiones, es preciso retomar el trabajo de esta autora, Del elogio a la injuria. La escritora como mito en el imaginario cultural de los años 20 y 30 donde se aborda desde una perspectiva transdisciplinar entre la historia y la teoría literaria los modos de figurar en la prensa los modelos de escritora en esta década, y las producciones de tres escritoras importantes del período en diálogo con esos modos: Victoria Ocampo, Alfonsina Storni y Salvadora Medina Onrubia.
}

Revista Zona Franca- Centro de estudios interdisciplinario sobre las mujeres (CEIM)- Maestría poder y sociedad desde la problemática de género (MG), Rosario, Argentina. ISSN, 2545-6504 http://zonafranca.unr.edu.ar/index.php/ZonaFrancal Número 28 (2020). 


\section{Tradiciones y revisiones críticas}

Cada relato implica un procedimiento de recorte: lo nacional, lo histórico y lo literario está atravesado por esta intención de construir y presentarse como un todo homogéneo, progresivo, lineal, donde las tensiones y disquisiciones en torno lo dicho y lo no dicho no sean transparentes, ya que responden a la lógica de la ideología (Eagleton, 2013). Pero el canon, y así las historias de la literatura, puede ser revisado, interpelado e intervenido. Esto se debe a que el canon, como todo territorio de intervención política, se estructura como "un campo de fuerzas [...] atravesado por relaciones de poder que gobiernan prácticas, discursos, representaciones, cuerpos e identidades mediante sistemas de imposición, subyugación y exclusión de lo que no se ajusta a sus reglas de dominancia" (Richard, 2011: 465). En el potencial rescate y estudio de aquello excluido es que radica entonces la intervención que, pensada desde una mirada feminista (Pollock, 2019), resulta pertinente si queremos repreguntarnos acerca de estos procesos de constitución de una tradición literaria poniendo el foco en aquellas figuraciones y categorías - de autor, de obra- perpetuadas como estancas, como inherentes a la literatura argentina. La categoría de "intervención" entonces reflexiona acerca de la posibilidad de desmontar los cimientos discursivos y aquellos artilugios cargados de ideologemas mediante los cuales se entrelaza el relato de las historias del arte en general, y de la literatura argentina en particular. ${ }^{\vee}$ Para intervenir de forma feminista no solamente hace falta "deconstruir la fabricación ideológica que privilegia al individuo masculino en el discurso de la historia del arte" (39) sino también una mirada feminista materialista. Esta mirada, a su vez, parte

No desde la presunción de que existe una esencia femenina por fuera de las condiciones sociales, o parcialmente inmune a ellas, sino desde el análisis de la relación dialéctica entre el hecho de ser una persona posicionada en lo denominado

\footnotetext{
$\checkmark$ Sobre los procedimientos narrativos que conforman el relato de la historia de modo que se genera la ilusión de que esta se estuviera contando sola desde una perspectiva presuntamente neutral, imparcial y objetiva, véase Hayden White (1992).
}

Revista Zona Franca- Centro de estudios interdisciplinario sobre las mujeres (CEIM)- Maestría poder y sociedad desde la problemática de género (MG), Rosario, Argentina. ISSN, 2545-6504 http://zonafranca.unr.edu.ar/index.php/ZonaFranca| Número 28 (2020). 
<<femenino>> dentro de los órdenes sociales que varían con la historia y las maneras históricamente específicas en que nos salimos siempre de esa posición (36).

En esta forma de revisionismo de las historias de la literatura, el género no se entiende como una categoría dada sino -al igual que la categoría de clase o razacomo un término que traslada en sí mismo todas las contradicciones y disputas de una época histórica concreta en relación a las formas materiales de existencia y a los efectos que resultan de esa construcción. En tales efectos se pueden leer también las relaciones que determinan y se determinan en la producción y sus implicancias culturales. Es por eso que toda tarea de intervención debe ser acompañada por un doble giro epistémico que implica no solamente mencionar a una escritora o algunas escritoras que produjeron literatura en determinado momento histórico sino también articular esta mención con una reflexión; reescribir esta historia que en un principio no las consideraba parte central de sí. Reescritura que debe dar cuenta de esas resistencias específicas a esos modos esencialistas de leer, de producir crítica, de producir literatura y de perpetuar la discriminación y los paradigmas androcéntricos. En ese sentido cabe preguntarse ¿cómo se manifiesta el androcentrismo? ¿es siempre androcéntrica la crítica literaria y la historia de la literatura?

A la vez, es necesario retomar los protocolos que elabora Guadalupe Maradei (2012) en "Disparar contra el canon: la literatura escrita por mujeres en las nuevas historias de la literatura argentina". La autora sostiene que es necesario cuestionar aquellos paradigmas que confirman el sentido común y perpetúan y legitiman las exclusiones respecto a las instituciones para poder corromper, desde el espacio canónico, aquellos lugares eternamente asignados a un modelo de sujeto social. Además, revisa ciertas figuraciones de escritoras en algunas historias de la literatura argentina que fueron elaboradas y publicadas luego de la última dictadura cívico militar. En su análisis del "núcleo problemático vigente en la reflexión crítica en torno de la literatura escrita por mujeres" (175) se desarrolla una hermenéutica reflexiva

Revista Zona Franca- Centro de estudios interdisciplinario sobre las mujeres (CEIM)- Maestría poder y sociedad desde la problemática de género (MG), Rosario, Argentina. ISSN, 2545-6504 http://zonafranca.unr.edu.ar/index.php/ZonaFranca| Número 28 (2020). 
acerca de las intervenciones de la crítica literaria en relación con la importancia que adquiere la producción de escritoras en este período.

Con las articulaciones de ambas teorías nos acercamos al problema de las inclusiones de "cupo femenino", el cual fue y sigue siendo una demanda histórica del activismo feminista para sopesar la injusta imparidad en las inserciones de las mujeres en diversos ámbitos de la sociedad. La discriminación positiva, de este modo, le ha puesto una especie de parche al problema de la accesibilidad pero no termina de construir andamiajes teóricos, epistemológicos y críticos a la hora de articular reflexiones sobre los modos de pensar y estructurar los cánones. Entonces, para intervenir de forma feminista en las historias de la literatura es también necesario "construir una máquina de lectura que pueda conectar con el reverso de las dicotomías" (157) y desarticular ciertos enunciados que más que elaborar un panorama de situación siguen perpetuando la exclusión. ${ }^{\mathrm{VI}}$ De esto también se ha encargado desde los años '80 una gran cantidad de críticas literarias feministas formadas en estudios de género, quienes han retomado la producción literaria de este período y obras que no fueron incluidas en las historias de la literatura. Hay en todas las historias un fuerte ímpetu de cuestionar aquello que se toma como dado en la construcción de lo literario y lo nacional, y a lo largo de los años se cuestionan y deconstruyen categorías como "nación", "literatura" y "obra", incluso la noción de "historia", en relación a cada criterio elegido como principio constructivo de las historias mismas. Sin embargo, la idea de autoría sigue estando intacta e identificada con la masculinidad, aun cuando los movimientos feministas se han encargado de desnaturalizar aquella esencia femenina y masculina en la que se leen los estatutos de "lo natural masculino", y "lo otro" femenino. Es decir que, a pesar de los avances, aquella diferencia sexual que se erigía desde los sectores dominantes a principios de siglo XX se manifiesta de diferentes modos, con traspiés,

VI Para una reflexión global en torno a la revisión y diálogos entre las historias de la literatura argentina, se puede consultar el trabajo compilado por Guadalupe Maradei (2019) en Historias de la literatura. Asedios desde el Sur; sobre los cambios en los paradigmas críticos en las historias de la literatura argentina postdictadura, el trabajo de la misma autora publicado en abril de este año, Contiendas en torno al canon. Las historias de la literatura argentina postdictadura.

Revista Zona Franca- Centro de estudios interdisciplinario sobre las mujeres (CEIM)- Maestría poder y sociedad desde la problemática de género (MG), Rosario, Argentina. ISSN, 2545-6504 http://zonafranca.unr.edu.ar/index.php/ZonaFranca| Número 28 (2020). 
con vacilaciones, con zonas de ruptura, a lo largo de las historias de la literatura argentina.

\section{Números y prejuicios}

En todos los textos relevados la cantidad de escritoras que figuran en relación con los escritores es menor y en números se ve muy concretamente esta diferencia. La primera historia publicada luego de la de Ricardo Rojas es la Historia de la literatura argentina de Rafael Arrieta (1959). En el tomo ya mencionado, cuyos colaboradores son todos varones, la cantidad de mujeres es de 21, en comparación a los escritores varones que son más de 100. El tomo se divide en un total de siete grandes capítulos articulados según géneros literarios; dentro de ellos a la vez se dividen varios subgéneros, de los que solamente el primero está dedicado a un autor: Leopoldo Lugones. VII La poesía, la novela, el cuento, la crítica y el ensayo, el teatro y la poesía de vanguardia se encuentran plagados de nombres masculinos, entre los que resalta solo un nombre femenino que lleva el título de un pequeño apartado, en el que se incluye una foto: Alfonsina Storni. La misma autora vuelve a aparecer cinco años más tarde en Literatura argentina y realidad política, de David Viñas (1964). En esta primera edición, Storni figura en el apartado denominado "Mujeres y compañeras", acompañada por Soledad Gustavo y Alicia Moreau de Justo. Cuatro mujeres más aparecen en el resto de los apartados de esta primera edición: Carmen Gándara, Beatriz Guido y Victoria Ocampo. VIII El nombre de Storni vuelve a resonar en un fascículo de los que conformaban la Historia de la literatura argentina del Centro Editor de América Latina, publicada ocho años después de la

\footnotetext{
VII Las autoras que menciona, además de Alfonsina Storni son: Emilia Bertolé, Margarita Abella Caprile, María de Villarino, Silvina Ocampo, Agustina Larreta de Álzaga, Margarita del Campo, Eloísa Ferraria Acosta, Nydia Lamarqué, Fryda Schultz de Mantovani, María Granata, María Elena Walsh, María Alicia Domínguez, Emma de la Barra de Llanos, Silvina Bullrich, Norah Lange Felisa de Onrubia, Ana María Berry, Luisa Sofovich, Rosa Bazán de Cámara y Sara Etchevers. Luego de las dos ediciones de CEAL, este es el tomo de una Historia de la literatura que más mujeres ha mencionado.

VIII Sobre las escrituras, cambios y reescrituras de este texto en sus distintas ediciones, véase Canala (2012).
}

Revista Zona Franca- Centro de estudios interdisciplinario sobre las mujeres (CEIM)- Maestría poder y sociedad desde la problemática de género (MG), Rosario, Argentina. ISSN, 2545-6504 http://zonafranca.unr.edu.ar/index.php/ZonaFrancal Número 28 (2020). Página 464 
de Arrieta. IX De los 59 fascículos que se publicaron entre 1967 y 1968, el número 34 es el dedicado a Alfonsina Storni, la única escritora que figura como criterio constructivo de un fascículo. En la edición de 1995 de Literatura argentina y política, David Viñas agrega algunos nombres más y con ellas, algunas claves de lectura. En los volúmenes colectivos que dirige de Literatura Argentina Siglo XX, si bien elige a dos mujeres críticas como compiladoras para los tomos II y III, la condición de minoría en tanto representatividad numérica se sigue manteniendo: de un total de 598 publicaciones, 25 corresponden a producciones de mujeres a desglosar en 7 autoras en el tomo II, y de un total de 212 publicaciones, 14 corresponden a 8 mujeres en el tomo III. ${ }^{X}$ Por último, en el tomo VI de la Historia crítica de la literatura argentina. El imperio realista, hay 3 artículos en los que se mencionan autoras mujeres del período de un total de 20 artículos sobre este género tan característico de las primeras décadas del siglo XX. $\mathrm{XI}$

Esta proporción desigual se repite en la Breve historia de la literatura argentina de Martín Prieto (2006) y en los demás tomos de la Historia crítica de la literatura argentina de Noé Jitrik que abordan el período. En la única historia que se equiparan un poco las proporciones, es en la segunda edición a cargo de Susana Zanetti de la Historia de la literatura argentina del Centro Editor de América Latina, publicada entre los años 1980 y 1981. Además del fascículo dedicado a Alfonsina Storni presente en la primera edición, en el volúmen III Las primeras décadas del siglo se agrega uno a cargo de Élida Ruiz dedicado a las escritoras mujeres que publicaron entre 1840 y 1940 . Allí, el número de escritoras mencionado es de 108, todas nucleadas en ese capítulo aparte. En el IV, Los proyectos de la vanguardia, se agrega un artículo a cargo de Noemí Ulla sobre Silvina Ocampo -al igual que en el

\footnotetext{
Ix Sobre la primera edición de Capítulo, la historia de la literatura argentina, véase Barral (2019).

$x$ Los nombres que menciona son los de Alfonsina Storni, Margarita Abella Caprile, Delfina Bunge de Gálvez, Victoria Ocampo, Norah Lange, María Alicia Domínguez y Emilia Bertolé en el tomo II, a las que se agregan Renata Donghi de Halperín, María Luisa Carnelli, Rosario B. Núñez y Silvina Ocampo en el III.

${ }^{\mathrm{XI}}$ Las escritoras son Silvina y Victoria Ocampo, María Rosa Olivier, Nydia Lamarqué, Raquel Adler y Amparo Mom. A diferencia de Rupturas, el tomo siguiente en el plan de obra, no hay ningún artículo dedicado específicamente al análisis de la obra de alguna escritora.
}

Revista Zona Franca- Centro de estudios interdisciplinario sobre las mujeres (CEIM)- Maestría poder y sociedad desde la problemática de género (MG), Rosario, Argentina. ISSN, 2545-6504 http://zonafranca.unr.edu.ar/index.php/ZonaFranca| Número 28 (2020). Página 465 
de Storni, el criterio constructivo es el nombre propio- en el que se mencionan además dos críticas literarias que han estudiado su obra, junto a su hermana Victoria.

Una primera mirada, intuitiva si se quiere, en relación con las condiciones de exclusión es que la cuestión de la imparidad en la representación es, en cierto sentido, una de las formas de perpetuar estas condiciones de exclusión. Otras formas de hacerlo, a la vez, se trazan en ciertos modos que tiene la crítica de seguir reproduciendo algunos prejuicios en torno a las figuras de las escritoras. Estos encuentran, en parte, edificación en ciertas lecturas esencialistas y se han cristalizado a lo largo de la historia de la literatura y de los textos de las historias de la literatura. En dichas lecturas se utilizan frases como "condición femenina" o "feminidad", a priori y de manera forzada en los textos, es decir, no se lee un texto como visaje a una experiencia de género (cosa que también podría hacerse en el caso de un escritor varón) sino que se leen las marcas del género y de esa experiencia antes que la forma y el contenido de un texto de manera causal. De "la condición femenina" se desprenden entonces ciertas cuestiones en relación con la escritura. Desde ese modo biografista, se jerarquiza el artilugio creado en torno al personaje de la escritora por sobre sus obras, y se pierde lo literario y su politicidad. Al jerarquizar la firma (un nombre de escritora y así, su biografía) se pierden de vista no solamente los textos sino también las condiciones de producción, los modos de circulación e itinerancias, y las posibles circunstancias en las que el texto rompe con el contexto en el que surge (Derrida, 1998). Por ejemplo: "La segunda publicación ultraísta [...] confirmaba la profesión de fé [...] de sus colaboradores: Borges, González Lanuza, Guillermo de Torre, Roberto Ortelli, Sergio Piñero, Jacobo Sureda, la entonces jovencísima Norah Lange, que tenía sólo 16 años" (Prieto, 2006: 133, el subrayado es mío). Este modelo se repite en otras publicaciones de la misma forma: de las mujeres se detalla cómo y dónde vivían, si tenían hijos y otros detalles de la vida personal que no solamente no dicen nada de sus

Revista Zona Franca- Centro de estudios interdisciplinario sobre las mujeres (CEIM)- Maestría poder y sociedad desde la problemática de género (MG), Rosario, Argentina. ISSN, 2545-6504 http://zonafranca.unr.edu.ar/index.php/ZonaFranca| Número 28 (2020).

Página 466 
publicaciones y producciones, sino que tampoco se detallan en el caso de los escritores varones. Otro ejemplo:

Victoria Ocampo dota a la nota introductoria de su revista, más que de feminismo, de pura feminidad, relatando un paseo de octubre de 1929 por el bosque de Palermo, junto con Waldo Frank: "Usted me reprochaba con violencia mi inactividad, y yo le reprochaba, no menos violentamente, que me supusiera usted apta para ciertas labores. Entonces, por primera vez, el nombre de esta revista — que no tenía nombre— fue pronunciado". (171)

Nuevamente, no hay demasiada correlación entre el paseo con Frank y la "pura feminidad" de la nota introductoria de la revista.

Otro prejuicio que abunda a la hora de pensar la literatura producida por mujeres y también, su mantenida exclusión, es el que sostiene "las revistas y la vida literaria en general eran, y lo seguirán siendo por muchos años, acontecimientos estrictamente masculinos" (171). Esta frase, más que una idea aislada en una historia o modos de hacer crítica en particular, se toma como condición ontológica evidente, y a lo largo del tiempo se repite sin siquiera tematizar o problematizar las implicancias de decir que un territorio o acontecimiento es en sí mismo estrictamente masculino. Sin embargo, "los signos 'hombre' y 'mujer' son construcciones discursivas, montajes representacionales que ocultan sus organizaciones de significados tras la falsa apariencia ("naturaleza") de una verdad

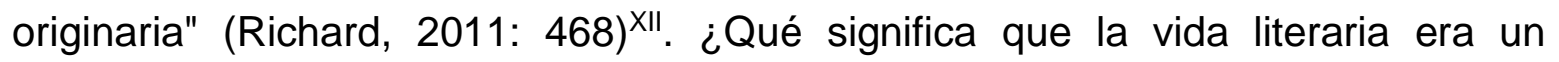
acontecimiento estrictamente masculino? ¿Qué hacemos, entonces, con los nombres que aparecen en el artículo de Élida Ruiz en la edición del '81 de la historia del Centro Editor de América Latina, o mismo con los que aparecen en la de Arrieta? ¿ellas no formaban parte de la vida literaria y de las revistas? ¿dónde publicaban

\footnotetext{
XII Los lineamientos de Richard en su teoría son una lúcida lectura aplicada al caso latinoamericano de lo señalado por Butler (1990) en El género en disputa. Allí se explican de forma exhaustiva los aportes de la teoría lesbiana materialista a la hora de comprender los efectos y manifestaciones en la conciencia y en los cuerpos de los sujetos de la opresión, específicamente del "mito de la mujer" que no existía antes de que existiera la opresión ya que se encuentra en lo denominado "formación imaginaria".
}

Revista Zona Franca- Centro de estudios interdisciplinario sobre las mujeres (CEIM)- Maestría poder y sociedad desde la problemática de género (MG), Rosario, Argentina. ISSN, 2545-6504 http://zonafranca.unr.edu.ar/index.php/ZonaFrancal Número 28 (2020). 
entonces? Como señala Butler (1990), el lenguaje o las formaciones discursivas no son en su definición pero sí en su potencial herramientas constructivas de enunciados falogocéntricos. Decir que la literatura era un acontecimiento masculino y decirlo en 2006, luego de que una trayectoria considerable de escritos de historiadoras, críticas literarias, artistas y epistemólogas feministas se encargaran de hacer diversas operaciones de rescate de las producciones de mujeres en los distintos períodos de la cultura nacional, es seguir perpetuando aquella exclusión en el relato - no en el acontecimiento - de los hechos literarios. En todo caso, lo que es estrictamente masculina es la representación y la narración de la construcción de la vida literaria, no la vida literaria en sí. Este modo de contar y concebir la historia literaria se debe a lo que Mignolo (1995: 25) señala:

El campo de los estudios literarios se concibe más como un corpus heterogéneo de prácticas discursivas y de artefactos culturales. El hecho de que alguna de ellas o de ellos adquiera estatuto canónico es parte de la complejidad de fuerzas sociales en conflicto pero de ninguna manera un fenómeno que naturalmente define el campo de estudios (el subrayado es mío).

Es decir que la exclusión de las escritoras o la inclusión de ellas en tanto excepción (que es, en parte, lo que se esconde detrás del "cupo") con esa constante exclusión en la representación no puede tomarse como inherente al campo de estudios ya que eso sería seguir relegando el estudio de la producción concreta de estas escritoras: qué escribieron, dónde publicaron, qué horizontes de recepción tenían sus producciones, y otras cuestiones en relación con la obra, y ya no con la o las escritora(s). Si bien en algunos casos se esbozan las intenciones, estas no se desarrollan. Ejemplos de esto son frases como "tan abundante ha sido la floración poética femenina en el medio siglo último que podría escribirse un panorama como éste con solo estudiar a la ligera la producción del casi centenar de mujeres cuyos nombres figuran en una Antología a ellas dedicada" (Arrieta, 1959: 82, el subrayado es mío) o "de ahí que autores como [...] Alfonsina Storni, sean aguijoneados insistentemente desde el "Parnaso Satírico", pero no forman parte, estrictamente

Revista Zona Franca- Centro de estudios interdisciplinario sobre las mujeres (CEIM)- Maestría poder y sociedad desde la problemática de género (MG), Rosario, Argentina. ISSN, 2545-6504 http://zonafranca.unr.edu.ar/index.php/ZonaFranca| Número 28 (2020). Página 468 
[...] del programa martínfierrista" (Prieto, 2006: 136). Es decir, hay una mención pero no se especifican más referencias de aquella producción - en el caso de Arrieta - o no se justifica la hipótesis de lectura mencionada - en el caso de Prieto -. A la vez se repite la forma de constelar escritoras en función de escritores. Si los nombres masculinos son representativos de períodos enteros, de generaciones estéticas o movimientos literarios, las mujeres siempre se insertan dentro de estos movimientos liderados por figuras masculinas y no forman un sistema literario propio. Es habitual leer títulos de capítulos como "Carriego en cámara lenta", "Payró: periodismo y postergación", "Rojas, rebeldía y respetabilidad", "Borges: una vanguardia criolla", "Güiraldes y Lynch: últimos gauchos en familia", o que determinado autor es representativo de un período literario; menos habitual, títulos como "Alfonsina Storni, Salvadora Medina Onrubia: La ruptura del pudor". XIII

Estos lineamientos de la crítica dejan ver "los modos de invisibilización sedimentados en los procesos de canonización" y, a la vez, ciertas "regulaciones que distintos discursos configuraron para la escritura de las mujeres" (Maradei, 2012: 169). En este sentido, delimitar ciertos modos de la exclusión de estas escritoras y simplemente mencionar sus nombres o qué y dónde escribieron es condición necesaria pero no suficiente para desmontar la manifestación de las diferencias sexuales en la crítica literaria argentina canónica, ya que "decir mujeres, incluirlas, no deja de producir un efecto de falsa completud y una ratificación del orden binario" (López, 2019: 69). Para poder empezar a pensar nuestras propias tretas del débil con los elementos que disponemos de la crítica y del canon epistémico, es preciso ver los modos de inclusión de estas escrituras y de sus escritoras, sus figuraciones e inserciones a estos relatos de la historia ya que a partir de ellas podremos elaborar nuestra propia "historia de la producción de la opacidad

\footnotetext{
XIII Mención aparte merece la reflexión acerca de la categoría de "autor", en sí misma patriarcal y por qué no, individualista, por la trama de sentidos que acarrea desde su fundación. Cabe interrogarse si necesitamos contraponerle una categoria equivalente como "autora", o si en realidad el sistema literario puede empezar a estudiarse desde otros ejes y puntos de vista que no sean lo individual o autoral. Sin embargo, la reconstrucción de un archivo de autor y de autora puede resultar importante para estudiar y comprender los contextos de publicación de las obras, y su valor en tanto fuentes históricas y literarias.
}

Revista Zona Franca- Centro de estudios interdisciplinario sobre las mujeres (CEIM)- Maestría poder y sociedad desde la problemática de género (MG), Rosario, Argentina. ISSN, 2545-6504 http://zonafranca.unr.edu.ar/index.php/ZonaFranca| Número 28 (2020). Página 469 
y del silencio $y$, fundamentalmente, de las condiciones de lucha que hacen posible romperlos" (67). También es preciso no conformarse con el espejismo (Fletcher, 2007) que "ve solamente a las grandes figuras, las que han logrado hacerse un nombre -por más disímil que sea el porqué del logro-en la historia literaria del país" y "desconoce la mayoría del corpus de textos literarios escritos por mujeres" (11).

\section{El Capítulo de ríos que se bifurcan}

En la cuarta edición de Literatura argentina y realidad política editada y publicada en el año 1995, David Viñas saca la palabra "realidad" y agrega al final de cada uno de sus capítulos los apartados "meandros, lecho, afluentes y embocaduras". En estos apartados el crítico realiza un montaje sobre cuestiones que o se desarrollaron en el capítulo anterior, o se relacionan con algún tópico a penas desplegado de forma tangencial. Estos retazos de lecturas desarrollan varias hipótesis sobre algunas mujeres escritoras, hipótesis que se habían esbozado en las anteriores ediciones pero sin mayores profundizaciones. Además, es interesante que todo lo referido a la producción literaria de escritoras lo incluya en el apartado denominado "meandro" ya que eso significa, según la geografía, aquella línea curva en la que el río toma un desvío o bifurcación. En el curso de la historia literaria, los meandros de Viñas se presentan como estas ondulaciones en las que es posible pensar, entre otras cosas, cuestiones en relación con la literatura producida por mujeres. ${ }^{X I V}$ En el primero de ellos, Viñas esboza hipótesis de lecturas que van en línea con lo planteado en el apartado "bohemia libertaria, mujeres y compañeras" en el que se menciona una "secuencia de señoras literatas inaugurada con la Gorriti" (Viñas, 2017: 280) de la que serían parte Alfonsina Storni, Alicia Moreau, Soledad Gustavo y Julieta Lanteri por su activismo y origen inmigratorio. Si bien hay un criterio de diferencia sexual que prima ("señoras literatas") para poner a aquellas escritoras en serie, es interesante que se menciona por primera vez la cuestión

XIV Esto plantea la pregunta acerca de los efectos de tomar como curso "natural" del río a la literatura mayormente masculina, y a los desvíos del mismo la femenina, es decir los efectos conservadores de plantear como naturales aquellas situaciones que están construidas socialmente.

Revista Zona Franca- Centro de estudios interdisciplinario sobre las mujeres (CEIM)- Maestría poder y sociedad desde la problemática de género (MG), Rosario, Argentina. ISSN, 2545-6504 http://zonafranca.unr.edu.ar/index.php/ZonaFranca| Número 28 (2020).

Página 470 
inmigratoria y de clase en relación con el activismo militante, como claves de lectura, cuestión que hasta entonces no se habían tenido en cuenta para otras escritoras que no fuesen Alfonsina Storni. En el segundo meandro reitera lo de la serie de señoras literatas y agrega en esta misma a Mariquita Sánchez de Thompson, Norah Lange, Emilia Bertolé, Herminia Brumana, Nydia Lamarque y Victoria Ocampo, "que, al despegarse de lo más trivial de su sociabilidad, irá agregando espesor a "su oficio" entremezclado, a veces, con sus rasgos de empresaria" (320). Se pone en primer plano el rasgo de leerlas como mujeres pero también de pensar su oficio y profesionalidad. De todas rescata, independientemente de su clase social, las distintas formas de desenvolverse en el campo cultural e intelectual, sus intereses o "fervores por todo lo europeo", entrecruzados con "didactismo" y distintos "estilos" que van inclinándose hacia la "crónica social" (321). Esto atraviesa distintos momentos en la historia de la literatura, que son los momentos que delimita concisamente en sus apartados de los que los meandros son corolario. En el tercero, Viñas va un poco más allá en sus lecturas, y menciona la discusión activa de las escritoras del período que le sigue a la crisis de la ciudad señorial:

Los contextos que permiten - por sus series de ecos y de rechazos entretejidos - una comprensión más ajustada de la versión lugoniana de la mujer planteada en El ángel de la sombra son varios [...]. Van dibujando, contradictoriamente, la escenografía de fondo sobre la que se recorta la voz lugoniana. Alfonsina Storni, desde su lateral, saludablemente descarada para ese momento, llega a decir: "yo nací para el amor". Coincidiendo en el mismo 1926 Delfina Bunge de Gálvez, se escandaliza en Los malos tiempos de hoy frente a la mujer "que se pone pantalones, usa pelo corto, fuma y quiere ser campeón de box". La izquierda bien pensante se suma a semejantes desahogos [...]. Menos mal que, en ese mismo año, César Tiempo acertó con su sagaz mistificación de la puta inmigrante en Versos de una atribuida a Clara Beter, que [...] puso el problema a foco junto a los "ladroncitos" de El juguete rabioso y en implícito cuestionamiento del presunto humor antisemita del Arturo Cancela de Una

Revista Zona Franca- Centro de estudios interdisciplinario sobre las mujeres (CEIM)- Maestría poder y sociedad desde la problemática de género (MG), Rosario, Argentina. ISSN, 2545-6504 http://zonafranca.unr.edu.ar/index.php/ZonaFrancal Número 28 (2020). 
semana de holgorio (cfr. Estela Dos Santos, Las cantantes 1986; Elisabeth

Roudinesco, Feminismo y revolución, 1987). (381) $\mathrm{xv}$

Las últimas dos citas teóricas son agregadas en la última edición, del año 2005, lo cual puede darnos algún indicio de que el autor estuvo actualizándose en ciertas lecturas acerca de los feminismos, o al menos estaba en su espectro de intereses elaborar protocolos de lectura que tuvieran que ver con este tema. En esta órbita puede pensarse también la incorporación de un artículo a su apéndice de esta edición Ilamado "El escritor como hombre blanco". Las series en la crítica de Viñas se forman según "estrategias que diseñan la organización del corpus analizado a partir de pares, de contrastes, de lecturas focalizadas en "el revés de la trama" (Canala, 2012: 86), y en ese sentido es interesante que incorpore la figura de Clara Beter como contrapunto de las interpelaciones de ciertas escritoras como Delfina Bunge y Alfonsina Storni. Esta intención podría verse más claramente en los tomos II (2002) y III (2003) de Literatura argentina siglo XX donde aparecen menciones no solamente de producciones literarias sino también de activismos políticos de algunas escritoras como es el caso de Salvadora Medina Onrubia, a quien en uno de sus meandros ya había rescatado como parte de la militancia anarquista.

Simultáneamente a que Viñas agrega estas dos citas en este párrafo dirige dos volúmenes colectivos que se elaboran con una intención un poco más activa de

xv Leopoldo Lugones en El ángel de la sombra (1994 [1926]) elabora en un boceto literario que mezcla procedimientos del folletín sentimental con materiales textuales provenientes de las ciencias ocultas lo que diez años antes, tan solo meses después de que se realizara en Buenos Aires el primer Congreso Internacional Femenino, había manifestado en "El problema feminista", aquel conocido ensayo publicado en La nación. Si en el ensayo concluye diciendo que "vale más la fecundidad de una madre que la producción intelectual de una doctora, porque las doctoras son reemplazables por los doctores, mientras sin madres deja de existir la patria", en su novela irá un paso más allá al atribuirle a las mujeres la condición angelical y describirlas como seres "vinculados a ningún interés capital, como la vida y la muerte, la bienaventuranza o la salvación, sino puramente de entidades de belleza" (35). En ese sentido, los ángeles de Lugones solo se hacen carne en los cuerpos de ciertas mujeres "para ser amadas [...] o para amar con amor humano" (34). Cabe destacar que la protagonista de la novela quien seduce a su humilde profesor con sus dotes angelicales sobrenaturales comparte nombre con la marquesa Eulalia. Sobran los intertextos para comprender por qué las escritoras de la época dialogaban con estos modelos femeninos consagrados en cierto sector de la literatura producida por sus colegas contemporáneos, y la cita contestataria, rescatada por Viñas de Alfonsina Storni.

Revista Zona Franca- Centro de estudios interdisciplinario sobre las mujeres (CEIM)- Maestría poder y sociedad desde la problemática de género (MG), Rosario, Argentina. ISSN, 2545-6504 http://zonafranca.unr.edu.ar/index.php/ZonaFrancal Número 28 (2020). 
pensar la producción de mujeres. Esto aparece en las dos introducciones de sendos volúmenes. En el caso del segundo, la directora menciona que "un rasgo novedoso de este período es que las minorías comienzan a escribir. Así aparece una importante literatura escrita por mujeres" (Montaldo, 2006: 28); en el caso del tercero:

Las escritoras mujeres parecen encontrar la legitimación de su propia escritura bajo el pretexto del recuerdo. Es claro en Victoria Ocampo este movimiento, que la lleva a la producción de Testimonios - casi: explicaciones que justifiquen su lugar en el mundo, ha dicho María Moreno -, pero también ese el movimiento que permite el pasaje a fuertes experimentaciones como Cuadernos de infancia de Norah Lange y Viaje olvidado de Silvina Ocampo (López, 2007: 30).

Estos artículos resultan distintivos en sus modos de leer la producción de mujeres ya que elaboran hipótesis que contemplan las condiciones de producción y recepción de los textos, a la vez que se toma en cuenta el material textual en concreto, con fuerte hincapié en el análisis estructural de procedimientos literarios, de sus formas y de su contenido. En ese sentido, dichas hipótesis dan cuenta de cómo estos escritos, entendidos como hechos estéticos y sociales, por un lado ponen en escena la "crisis del rol férreamente establecido por la sociedad para la mujer" (Muschietti, 2006: 114) y por otro, se resisten tanto en los modos de figuración como en sus modos de circulación al "vasto dispositivo armado desde los diferentes sectores capilares del poder" que suelen filtrar "numerosos indicadores ideológicos" (115) cuya raigambre de poco más de cien años, para comienzos del siglo XX, comenzaba a desestabilizarse.

En esa órbita hace sistema con el tomo VII de la Historia crítica de la literatura argentina, a cargo de Celina Manzoni y publicado en 2009; en su introducción y como declaración de principios se destaca que la génesis del tomo tiene la intención de "prestar atención a deslizamientos y entramados no convencionales, organizar nuevas cartografías culturales que reconfiguran zonas del sistema literario" (Manzoni, 2009: 9). Es decir que la mayor cantidad de escritoras mujeres en esta

Revista Zona Franca- Centro de estudios interdisciplinario sobre las mujeres (CEIM)- Maestría poder y sociedad desde la problemática de género (MG), Rosario, Argentina. ISSN, 2545-6504 http://zonafranca.unr.edu.ar/index.php/ZonaFranca| Número 28 (2020). 
historia dirigida por Noé Jitrik aparecen en el tomo que tiene la intención de analizar las transgresiones e interpelaciones al sistema literario en las características de su propia constitución. En este tomo se le dedican artículos enteros a Norah Lange en constelación con autores varones como Oliverio Girondo, Juan L. Ortiz, Amparo Mom y Luisa Sofovich, o basándose en sus procedimientos de vanguardia en relación con las rupturas del yo poético. En tándem con Güiraldes se lee a Victoria Ocampo, y en tándem con Storni - quien es junto con Victoria Ocampo y Norah Lange la escritora más mencionada de todo el período en absolutamente todas las historias de la literatura argentina - a Salvadora Medina Onrubia.

Por último, hace sistema con lo planteado tanto en el fascículo a cargo de Alfredo Veiravé del Centro Editor de América Latina, y el posterior agregado de 1981 de Élida Ruiz. ${ }^{\mathrm{XI}}$ Hace sistema en el sentido de que, al igual que los fascículos de Capítulo, no se realizan lecturas esencialistas o causales y hay intención tanto de mencionar o rescatar mujeres como de leer su obra y sus aportes desde su lugar en la literatura desmitificando la idea de ese territorio como estrictamente masculino. Este rescate había tenido lugar primero en la edición de 1968, en el fascículo "Feminismo y poesía: Alfonsina Storni". XVII Al interior del fascículo hay algunas cuestiones que vale la pena mencionar: en una de las primeras fotos, figura Storni junto a Adela García Salaverry, Margarita Abella Caprile, Mary Rega Molina y Emilia Bertolé. El encabezado reza "la presencia de la mujer en la literatura argentina es visible ya a partir del siglo XIX, pero en el XX se diversifica y amplía: lo certifican, dentro del género poético, nombres como los de Delfina Bunge de Gálvez, Margarita Abella Caprile, Emilia Bertolé, María Raquel Adler, y muchas otras" (Veiravé, 1968:

\footnotetext{
XVI Para las escritoras cuya producción conoció la luz en las siguientes décadas del siglo (1940-1970) se les designó un fascículo a Renata Rocco e Isabel Stratta, ubicado en el tomo V de esta segunda edición, "Ios contemporáneos".

XVII Si bien es discutible que el criterio organizador del fascículo sea el nombre propio, podemos pensar a la autora en su funcionalidad (Foucault, 1992) al igual que acontece con otros fascículos dedicados a escritores del período o de períodos posteriores. Además, Storni es analizada en serie con sus escritoras contemporáneas y quienes les fueron precursoras así que de ningún modo el dato biográfico o de la vida personal priman sobre lo estético o literario. El texto, por primera vez, le ha ganado a la persona de carne y hueso.
}

Revista Zona Franca- Centro de estudios interdisciplinario sobre las mujeres (CEIM)- Maestría poder y sociedad desde la problemática de género (MG), Rosario, Argentina. ISSN, 2545-6504 http://zonafranca.unr.edu.ar/index.php/ZonaFranca| Número 28 (2020). 
806. El subrayado es mío). Además, hay un apartado denominado "La mujer en la literatura argentina" que está acompañado de una foto de Alfonsina en el club de mujeres, y dice "con la irrupción de la mujer en la literatura argentina, llega a su fin un período de sumisión que había denunciado ya en verso Mariquita Sánchez de Thompson en el siglo anterior" (804). Al igual que Viñas, Veiravé pone en serie a Mariquita Sánchez de Thompson con Alfonsina Storni por tematizar directamente desde su poética el rol de las mujeres en la sociedad. Por último, otro apartado irrumpe con la lectura del resto del artículo y se denomina "Alfonsina Storni y el feminismo". Allí se menciona a "poetisas contemporáneas a Alfonsina Storni" y a "otras mujeres escritoras [...] que ocupan en la República Argentina un lugar destacado que expresan en un ambiente hostil a las luchas feministas" (811). El apartado concluye que

Con Alfonsina Storni se iniciaba en la literatura argentina, en forma definitiva, la incorporación de la mujer a la vida literaria en un mismo plano con el hombre. Pocos años después la Universidad Nacional de Montevideo reunió en un gran acto a las otras grandes poetisas de América: Gabriela Mistral, Juana de Ibarbourou y Alfonsina Storni. La batalla estaba definitivamente ganada" (812. El subrayado es mío). XVIII

Estas mismas tendrán un fascículo aparte, el número 58, a cargo de Élida Ruiz en la edición del 80, llamado "Las escritoras". En dicho fascículo se detalla que "se insertará la producción de las mujeres en un capítulo aparte" por ser "muy importante no sólo por el número sino también por la calidad" y afirma que "desde el comienzo de la escritura argentina la mujer colaboró en diarios y revistas, siendo incluso fundadora de algunos" (Ruiz, 1980a: 292). Es decir que se sigue la línea de lo planteado por Veiravé en el fascículo sobre Storni, y hace eco con lo dicho por Arrieta veinte años antes acerca del centenar de mujeres y su vasta producción.

XVIII El tono triunfalista y jocoso, muy propio de toda esta primera edición, desaparece por completo en la segunda. Es entendible debido a sus contextos de publicación, ya que en el año 1981 no había demasiadas batallas ganadas sino todo lo contrario. Sin embargo, la cita es iluminadora ya que atenta contra el imaginario que se seguiría sosteniendo incluso después, en las historias que le siguen, de que la literatura a principios de siglo XX era un acontecimiento estrictamente masculino.

Revista Zona Franca- Centro de estudios interdisciplinario sobre las mujeres (CEIM)- Maestría poder y sociedad desde la problemática de género (MG), Rosario, Argentina. ISSN, 2545-6504 http://zonafranca.unr.edu.ar/index.php/ZonaFranca| Número 28 (2020). 
Con este mismo criterio autoral se elabora un fascículo sobre Silvina Ocampo, incorporado en el tomo IV de la segunda edición de esta historia, en donde se reclama que las recepciones de su literatura deberían tener un lugar "más notorio en nuestro país" (Ulla, 1980: 385). Sin embargo, la particularidad del fascículo de Ruiz es que venía con la opción de adquirirse acompañado de una antología de esta misma autora en la que se encuentran fragmentos de producciones de 33 de esas 108 mujeres mencionadas. En el prólogo a la antología, la autora declama "El siglo $\mathrm{XX}$, con los aportes modernistas, neorrománticos, ultraístas, abre otras posibilidades literarias, que la mujer supo utilizar escribiendo obras que se alejan del romanticismo y del didactismo inicial", producciones que "barren con los prejuicios de la Colonia" (Ruiz: 1980b, 10). Se aclara además en la primera página que "esta selección tiene fundamentalmente carácter didáctico e informativo" dejando entrever que la intención es puramente de difusión y no un estudio cualitativo y exhaustivo de muchas escritoras del período. En ese sentido, se aclara como pretensión "mostrar las distintas incursiones que la mujer ha hecho en la literatura" ya que "la mujer no solo habló de amor, tema que parecía el único adecuado para ella, sino que pudo encarar obras de historia, relatos de viaje, narraciones heroicas, fantasías emotivas, biografías personales" (1). En estas citas se pueden ver la discusión activa con el ideal lugoniano que mencionaba Viñas, y también una intención de rebatir el prejuicio ya mencionado acerca de que las mujeres no participaban de la vida literaria. Algo a remarcar de esta segunda edición es que la palabra "feminismo" se quita del título del fascículo sobre Storni, que pasa a llamarse solamente "Alfonsina Sotrni". También se quita entero el apartado "Alfonsina Storni y el feminismo", y no se menciona en ningún momento del artículo de Ruiz, ni del de Ulla, ni del de Veiravé, ni siquiera en la antología. XIX Sin embargo, aquello que no se nombra encuentra otras formas de existir.

XIX Este fascículo de la primera a la segunda edición sufre cambios que pasan de incorporar a Storni con una serie de constelación de escritoras a realzar su figura individual: una foto de ella junto con Adela García Salaverry, Margarita Abella Caprile, Mary Rega Molina y Emilia Bertolé que en la edición del 81 es cambiada por una de ella, sola, presentando un libro en la editorial Signo. A la vez, el apartado de "La mujer en la literatura argentina" es reemplazado por la cronología de la vida de

Revista Zona Franca- Centro de estudios interdisciplinario sobre las mujeres (CEIM)- Maestría poder y sociedad desde la problemática de género (MG), Rosario, Argentina. ISSN, 2545-6504 http://zonafranca.unr.edu.ar/index.php/ZonaFranca| Número 28 (2020). 


\section{Un asunto pendiente}

A pesar de la notable desproporción entre escritores y escritoras, lo que he podido divisar en el análisis de estos pasajes que se refieren a las escritoras y a sus obras es que la diferencia sexual no siempre conlleva una invisibilización de las escritoras en el relato histórico. La metodología crítica, las claves de lectura que se ofrecen en las figuraciones y las series armadas dan cuenta de que excluir no necesariamente es invisibilizar y que a veces los silencios dicen más que la seguidilla de nombres atiborrados uno detrás del otro. Pasado este primer paso de atención a las figuraciones y a los modos de trabajo desde el canon, creo pertinente cuestionar qué se hace, cómo proceder luego del hallazgo de esta seguidilla de nombres y de datos sobre textos literarios y qué hacemos además de denunciar la imparidad para que ese evidenciar la disonancia no se convierta en esterilidad. A la vez, siempre que se insertan en clave de "excepción", "cupo" o "literatura de mujeres", "las escritoras que rompen con la masculinidad del ámbito literario", no se realiza una pregunta acerca de cómo deberían conformarse las perspectivas teóricas sino que se naturaliza lo ya dado y se deja en segundo plano la posibilidad de conformar series alternativas teniendo en cuenta otros criterios (sincrónicos, pertenecientes a movimientos estéticos, diacrónicos, u otros). De esta manera se desplaza continuamente a la literatura producida por mujeres a cierta subliteratura dentro del corpus de literatura nacional; los efectos, como ya vimos, son que la diferenciación termina por dejar afuera, sin leer desde los criterios considerados

Storni, aunque se deja una foto de ella en el club de mujeres. Al momento, desconocemos el motivo de estas modificaciones. Lo que sí sabemos en que, entre la primera edición y la segunda, acontecen varios hechos importantes para los feminismos en la Argentina: el número de la revista Sur dedicado a la mujer, en 1971; la fundación del Movimiento de Liberación Femenina y de la Unión Feminista Argentina entre cuyas militantes era difundida la lectura de El segundo sexo (Tarducci, 2019). Es decir que tanto en los sectores de las izquierdas y militancias universitarias, como en los asociados a la derecha se estaban pensando cuestiones en relación con el rol de la mujer, de manera masiva y colectiva. Tan solo un año después del conocido número de Sur Lily Sosa de Newton publica su diccionario biográfico de mujeres argentinas, citado por Élida Ruiz en la bibliografía de su artículo y de donde, se puede intuir, habría sacado algunas fuentes de los nombres que menciona allí (algunas de estas mujeres, sin embargo, no aparecen en el diccionario, ni siquiera en los recónditos pagos de internet).

Revista Zona Franca- Centro de estudios interdisciplinario sobre las mujeres (CEIM)- Maestría poder y sociedad desde la problemática de género (MG), Rosario, Argentina. ISSN, 2545-6504 http://zonafranca.unr.edu.ar/index.php/ZonaFranca| Número 28 (2020). 
centrales, a esta producción. En lo leído y lo relevado el estudio exhaustivo ya no de los datos biográficos sino de la producción de escritoras más allá del carácter "excepcional" y desde una perspectiva feminista se manifiesta como una carta de intención, un asunto pendiente que tiene la crítica y se ha postergado. Calificarlas de marginales permite, en parte, dar cuenta de cierta potencia subversiva de sus textos que tiene lo contra canónico, pero las consecuencias son ampliamente mayores ya que en los programas de estudios, en los textos que dan cuenta de la historia literaria, en las diferentes esferas de las institucionalizaciones que abarcan las lecturas y las críticas se sigue respondiendo a ese criterio que es completamente funcional al patriarcado. Esto no significa que haya que leerlas canónicamente porque son mujeres; decir eso sería reproducir nosotros también el esencialismo y caer en los mismos artificios que criticamos. Es pertinente leer canónicamente su literatura, enseñarla en las escuelas, estudiarla en las universidades porque en los poros de estas producciones ingresan - al igual que en la de sus contemporáneos varones - las angustias y querellas del momento histórico en el que escriben. Porque allí, en los materiales textuales, en sus distintas figuraciones y entramados, en sus procedimientos, en sus tópicos y personajes también pueden leerse las contradicciones y problemáticas de clase, de género, de raza. Es pertinente leerlas porque la resistencia o la respuesta a cierta moral, a los estereotipos, a las opresiones es un asunto que le atañe a la crítica literaria. Es nuestra tarea combatir activamente esa disputa por la representación enseñando modos de lectura feminista y con perspectiva de género que sean transversales e integren los protocolos de lectura, y no como una cuestión aparte o externa al texto, como una alternativa a la lectura "modelo". Como detalla llona Aczel (2019) "la historia literaria se presenta así como una guerra continua de cánones que se renuevan constantemente" de modo que "en el pasaje de la pregunta por el autor a la focalización en las instituciones que definen los contextos sociales que lo formulan" (369) podemos pensar una intervención sobre el canon que apunte a renovarlo desde una mirada con perspectiva de género. Cambiando los interrogantes mediante los cuales ingresamos a los textos se puede

Revista Zona Franca- Centro de estudios interdisciplinario sobre las mujeres (CEIM)- Maestría poder y sociedad desde la problemática de género (MG), Rosario, Argentina. ISSN, 2545-6504 http://zonafranca.unr.edu.ar/index.php/ZonaFranca| Número 28 (2020).

Página 478 
Entrever un funcionamiento más dinámico de la esfera literaria, no centrado en la voluntad o el genio de un autor individual o meramente determinado por su momento histórico, sino como una mera construcción colectiva y planificada de producción, legitimación y circulación de textos, permanentemente en conflicto y desplazamiento, que supone e indaga en el proceso de producción material de la esfera literaria y en su institucionalización (368).

Quizás sea pensar las contradicciones de la historia desde nuestra perspectiva de género que no viene forjada de antemano, sino que se forma mediante lecturas e interrogaciones y sobre todo, desde incomodarse y repensar las categorías ya establecidas. Repensar qué se dice cuando se dice "canon", o "cupo" que, si bien dan cuenta de una serie de pujas en relación al poder y a las instituciones siguen siendo forjadas desde y funcionales a ese poder. Repreguntar y preguntarnos todo. Allí, desde el silencio o desde la escritura; desde las grietas que tiene nuestra historia, desde los surcos del archivo y de los corpus alternativos; armar y reagrupar las series una y otra vez hasta que la exclusión y la diferencia sexual infundada dejen de ser moneda corriente en las formas de producir conocimiento y crítica literaria.

\section{Bibliografía}

ACZEL, Ilona (2019) "Esteban Echeverría y Juan María Gutiérrez, la(s) fundacion(es) de la literatura argentina" en Historias de la literatura. Asedios desde el sur, Editorial de la Facultad de Filosofía y Letras, Ciudad Autónoma de Buenos Aires.

ARRIETA, Rafael Alberto (1959) Historia de la literatura argentina, Peuser, Buenos Aires.

BARRAL, Manuela (2019) “Capítulo (1967-1968) cómo contar la historia de la literatura argentina en una publicación de fascículos semanales", Orbis tertius, 24 (30)

BRAIDOTTI, Rosi (2004) Feminismo, diferencia sexual y subjetividad nómade, Gedisa, Barcelona.

Revista Zona Franca- Centro de estudios interdisciplinario sobre las mujeres (CEIM)- Maestría poder y sociedad desde la problemática de género (MG), Rosario, Argentina. ISSN, 2545-6504 http://zonafranca.unr.edu.ar/index.php/ZonaFranca| Número 28 (2020). 
BUTLER, Judith (2018) El género en disputa, Paidós, Buenos Aires.

CANALA, Juan Pablo (2012) "Mansilla y Viñas: desvelo de archivo", La Biblioteca, 12, Buenos Aires.

DERRIDA, Jacques (1998) "Firma, acontecimiento y contexto", Márgenes de la filosofía, Cátedra, Madrid, pp. 347-372.

DIZ, Tania (2012) "Del elogio a la injuria. La escritora como mito en el imaginario cultural de los 20 y 30", La biblioteca, 1 (1-12).

EAGLETON, Terry (2013) Marxismo y crítica literaria, Paidós, Buenos Aires.

FLETCHER, Lea (2007) Narrativa de mujeres argentinas: bibliografía de los siglos XIX y XX, Feminaria Editora, Buenos Aires.

FOUCAULT, Michel (1984) “¿Qué es un autor?” En: Conjetural, №4, Agosto.

IRIGARAY, Luce (2004) An ethics of sexual difference, Continuum, New York.

LÓPEZ, María Pía (2007) "30/43: Historia, ensayo y literatura” en Viñas, David (dir) (2007) Literatura Argentina Siglo XX: La década infame y los escritores suicidas. Vol III, Paradiso, Buenos Aires, páginas 11-39

LÓPEZ, María Pía (2019) Apuntes para las militancias. Feminismos: promesas y combates, Eme, La Plata.

LUGONES, Leopoldo (1916) "El problema feminista”, Imprenta Greñas, San José de Costa Rica. Disponible en: https://www.marxists.org/espanol/tematica/mujer/autores/lugones/el problema fe minista/index.htm. Fecha de última consulta: 19/10/2020

LUGONES, Leopoldo (1994 [1926]) El ángel de la sombra, Losada, Buenos Aires

MANZONI, Celina (2009). "Introducción: rupturas" en Jitrik, Noé (dir) (2009) Historia crítica de la literatura argentina, vol VII: Rupturas. Emecé, Buenos Aires. Páginas 7- 10

MARADEI, Guadalupe (2012) "Disparar contra el canon: la literatura escrita por mujeres en las nuevas historias de la literatura argentina", Cuadernos del Sur Letras, n42, páginas155-178.

Revista Zona Franca- Centro de estudios interdisciplinario sobre las mujeres (CEIM)- Maestría poder y sociedad desde la problemática de género (MG), Rosario, Argentina. ISSN, 2545-6504 http://zonafranca.unr.edu.ar/index.php/ZonaFranca| Número 28 (2020). 
MARADEI, Guadalupe (2019) (comp) Historias de la literatura. Asedios desde el sur, Editorial de la Facultad de Filosofía y Letras Universidad de Buenos Aires, Buenos Aires.

MARADEI, Guadalupe (2020) Contiendas en torno al canon. Las historias de la literatura argentina postdictadura, Corregidor, Buenos Aires.

MASIELLO, Francine (1998) Entre civilización y barbarie. Mujeres, Nación y Cultura literaria en la Argentina moderna, Beatriz Viterbo Editora, Rosario.

MIGNOLO, Walter (1995) "Entre el canon y el corpus. Alternativas para los estudios literarios y culturales en y sobre América Latina" Nuevo Texto Crítico 7(1), 23-36. doi:10.1353/ntc.1994.0027. Fecha de última consulta 27/07/2020

MONTALDO, Graciela (2006) "Consagraciones: tonos y polémicas" en Viñas, David (dir) (2006) Literatura Argentina Siglo XX, tomo II: Yrigoyen entre Borges y Arlt (1916-1930), Paradiso, Buenos Aires. Páginas 30-42.

MUSCHIETTI, Delfina (2006) "Mujeres, feminismo y literatura" en Viñas, David (dir) (2006) Literatura argentina siglo XX, tomo II. Yrigoyen entre Borges y Arlt, (1926-1930), Paradiso, Buenos Aires. Páginas 111-133.

POLLOCK, Griselda (2019) Visión y diferencia. Feminismo, feminidad e historias del arte, Fiordo, Buenos Aires.

PRIETO, Martín (2006) Breve historia de la literatura argentina, Taurus, Buenos Aires.

RICHARD, Nelly (2008) Feminismo, género y diferencia (s), Palinodia, Santiago de Chile.

RICHARD, Nelly (2011) “¿Qué es un territorio de intervención política?” en AAVV (2011) Por un feminismo sin mujeres, fragmentos del segundo circuito de disidencia sexual, CUDS, Santiago de Chile.

RUIZ, Élida (1980a) "Las escritoras" en Zanetti (comp) Capítulo, la historia de la literatura argentina, Vol III: las primeras décadas del siglo, Centro Editor de América Latina, Buenos Aires. Páginas 287-312.

RUIZ, Élida (1980b) JM Gorriti, C Duayen, M de Villarino y otras. Las escritoras 1840-1940, Centro Editor de América Latina, Buenos Aires.

Revista Zona Franca- Centro de estudios interdisciplinario sobre las mujeres (CEIM)- Maestría poder y sociedad desde la problemática de género (MG), Rosario, Argentina. ISSN, 2545-6504 http://zonafranca.unr.edu.ar/index.php/ZonaFranca| Número 28 (2020). 
SALOMONE, Alicia (2006) Alfonsina Storni. Mujeres, modernidad y literatura, Corregidor, Buenos Aires.

SARLO, Beatriz (1988) Una modernidad periférica. Buenos Aires 1920 - 1930, Ediciones Nueva Visión, Buenos Aires.

TARDUCCI, Mónica (2019) “Todas queríamos ser como Simone. Las primeras lecturas de El segundo sexo en Argentina", Cadernos pagu, 56.

ULLA, Noemí (1980) "Silvina Ocampo" en Zanetti, Susana (comp) Capítulo, la historia de la literatura argentina, vol IV: los proyectos de la vanguardia, Centro Editor de América Latina, Buenos Aires. Páginas 385-408

VEIRAVÉ, Alfredo (1968) "Feminismo y poesía: Alfonsina Storni." Capítulo, 34 "la poesía en el avance del siglo", Buenos Aires, pp 793 - 816.

VIÑAS, David (1964) Literatura argentina y realidad política. Fray Mocho, Buenos Aires.

VIÑAS, David (2017 [2005]). Literatura argentina y política, Santiago Arcos Editor, Buenos Aires.

WHITE, Hayden (1992) El contenido de la forma. Narrativa, discurso y representación histórica, Paidós, Buenos Aires.

Revista Zona Franca- Centro de estudios interdisciplinario sobre las mujeres (CEIM)- Maestría poder y sociedad desde la problemática de género (MG), Rosario, Argentina. ISSN, 2545-6504 http://zonafranca.unr.edu.ar/index.php/ZonaFrancal Número 28 (2020). 